\title{
Four New Persian Walnut Cultivars of Iran: Persia, Caspian, Chaldoran, and Alvand
}

\author{
Darab Hassani \\ Temperate Fruits Research Center, Horticultural Sciences Research \\ Institute, Agricultural Research, Education and Extension Organization, \\ Karaj, Iran
}

\section{Mohammad Reza Mozaffari}

Agricultural and Natural Resources Research and Education Center of Kerman, Agricultural Research, Education and Extension Organization, Kerman, Iran

\section{Asghar Soleimani and Raana Dastjerdi}

Temperate Fruits Research Center, Horticultural Sciences Research Institute, Agricultural Research, Education and Extension Organization, Karaj, Iran

\section{Reza Rezaee}

Agricultural and Natural Resources Research and Education Center of West Azarbaijan, Agricultural Research, Education and Extension Organization, Urumia, Iran

\section{Mansureh Keshavarzi}

Temperate Fruits Research Center, Horticultural Sciences Research Institute, Agricultural Research, Education and Extension Organization, Karaj, Iran

\section{Kourosh Vahdati}

Department of Horticulture, College of Aburaihan, University of Tehran, Tehran, Iran

\section{Ahmad Fahadan \\ Agricultural and Natural Resources Research and Education Center of Khorasan Razavi, Agricultural Research, Education and Extension Organization, Mashhad, Iran}

\section{Jamal Atefi}

Temperate Fruits Research Center, Horticultural Sciences Research Institute, Agricultural Research, Education and Extension Organization, Karaj, Iran

Additional index words. breeding, early ripening, genotype selection, lateral bearing, high kernel percent, Juglans regia, late leafing behavior, protogynous flowering

Persian walnut (Juglans regia L.) is the second-most important nut crop grown in Iran. The number of walnut trees in that country is estimated to be more than 20 million, mostly seedlings, distributed on

Received for publication 6 Apr. 2020. Accepted for publication 4 May 2020.

Published online 17 June 2020

D.H. is the corresponding author: E-mail: d.hassani@ areeo.ac.ir or hassanida@gmail.com.

This is an open access article distributed under the CC BY-NC-ND license (https://creativecommons. org/licenses/by-nc-nd/4.0/). borders of farms and orchards or expanded in valleys. Total production of in-shell walnut is estimated at $400,000 \mathrm{t}$, and Iran is considered the third largest walnut producer in the world. Use of walnut seedling trees throughout the centuries has provided unique opportunities for breeders to select promising genotypes (Hassani, et al., 2014; McGranahan and Leslie, 2005; Vahdati et al., 2019). We report the main characteristics of four newly released commercial walnut cultivars-Persia, Caspian, Chaldoran, and Alvand - in Iran that are characterized by high yield, lateral fruitfulness, and early harvest.
In Iran, the walnut breeding program started in 1984 through the selection of native germplasm. This project led to the selection of some superior genotypes, of which two new cultivars, Jamal and Damavand, were released in 2010 (Hassani et al., 2012a, 2012b). The second phase of this program, with the aim of selecting for late leafing and lateral-bearing cultivars, was carried out during early 2000. A total of 39 promising walnut genotypes were selected from more than 41,000 ha of walnut plantations in the Alborz, Qazvin, Zanjan, West Azarbaijan, Kerman, Khorasan Razavi, Semnan, and Yazd Provinces. In 2006, the genotypes were grafted onto seedling rootstocks and were planted at a $7 \times 7$-m planting distance (square system) in a $6 \times 7$ lattice experimental design, with two replications and three trees per plot. The experimental orchard was established in Karaj (lat. $35.760560^{\circ} \mathrm{N}$, long. $50.96843^{\circ} \mathrm{E}$; elevation, $1268 \mathrm{~m}$ above sea level) and at the Rabor Walnut Research Station in Kerman Province (lat. $29.26264^{\circ} \mathrm{N}$, long. $57.04825^{\circ} \mathrm{E}$; elevation, $2300 \mathrm{~m}$ above sea level). Three commercial cultivars, including 'Chandler', 'Jamal' and 'Ronde de Montignac', were included in this trial as reference cultivars. Phenological and pomological characteristics of promising genotypes were studied until 2018. Four new cultivars were released in 2019 (Hassani et al., 2019).

\section{Methods}

Phenological and pomological traits of the selected cultivars were evaluated using International Plant Genetic Resources Institute (1994) and International Union for the Protection of New Varieties of Plants (1999) walnut descriptors. Moreover, the relative susceptibility of the new cultivars to anthracnose was tested as described by Dastjerdi and Hassani (2009). Blight and bark canker diseases were also evaluated as described by Silsepur et al. (2011) and Soleymani et al. (2019).

\section{Description}

'Persia'. 'Persia' is characterized by late leafing behavior (around 'Chandler' leafing date), which helps to avoid late-spring frosts (Supplemental Table 1, Supplemental Fig. 1). The protogynous flowering habits of this cultivar allows it to cross-pollinate with 'Chandler' (Supplemental Fig 1). It has a lateral bearing habit (Fig. 1), and most of the buds are productive $(60 \%$ to $80 \%)$. Vigor is intermediate. Yield in this cultivar is as high as 'Chandler' (Supplemental Table 1). Nut size is medium and nut weight is $10.5 \mathrm{~g}$, and the nut has a thin shell $(0.93 \mathrm{~mm})$ and a greater percentage of kernel $(63 \%)$ in comparison with 'Chandler' and other cultivars (Supplemental Table 2). The kernel is removed easily from the shell and has a light and extralight color. Kernel plumpness is good. The ripening time is earlymedium, about $25 \mathrm{~d}$ earlier than 'Chandler' (Supplemental Table 1, Supplemental Fig. 1). This cultivar is moderately resistant to anthracnose, bark canker, and blight. 


\section{Persia}

Leafing $1 \mathrm{~d}$ earlier $\mathrm{Ch}^{*}$

Harvest $27 \mathrm{~d}$ earlier $\mathrm{Ch}$
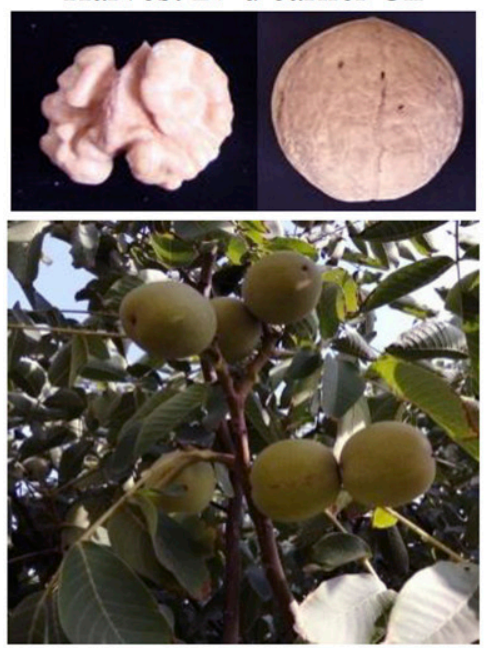

Caspian

Leafing $2 \mathrm{~d}$ later $\mathrm{Ch}$ Harvest $21 \mathrm{~d}$ earlier $\mathrm{Ch}$
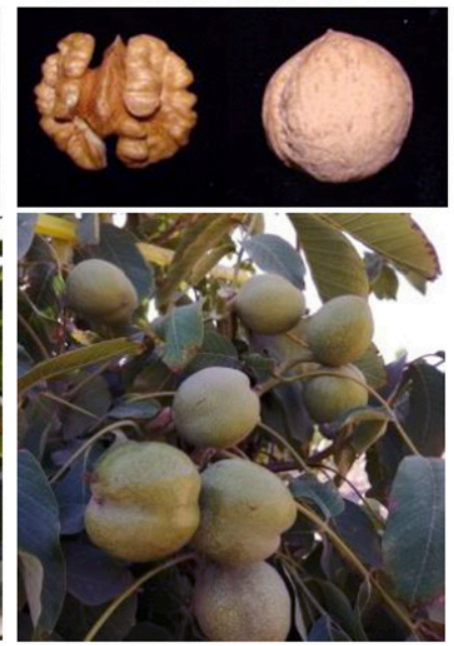

Alvand

Leafing $12 \mathrm{~d}$ earlier $\mathrm{Ch}$ Harvest 32 d Earlier Ch
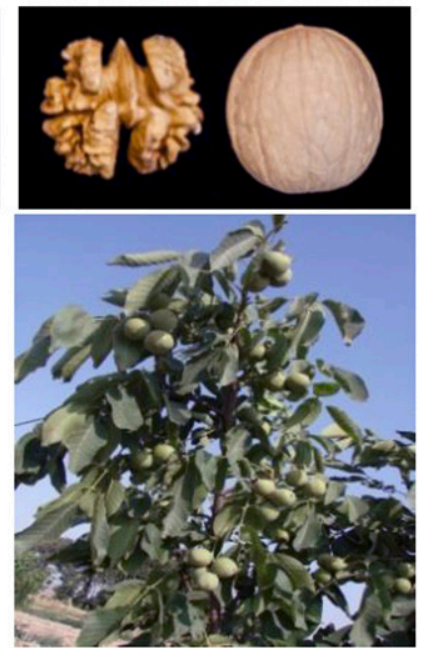

Chaldoran

Leafing $13 \mathrm{~d}$ earlier $\mathrm{Ch}$

Harvest $32 \mathrm{~d}$ earlier $\mathrm{Ch}$
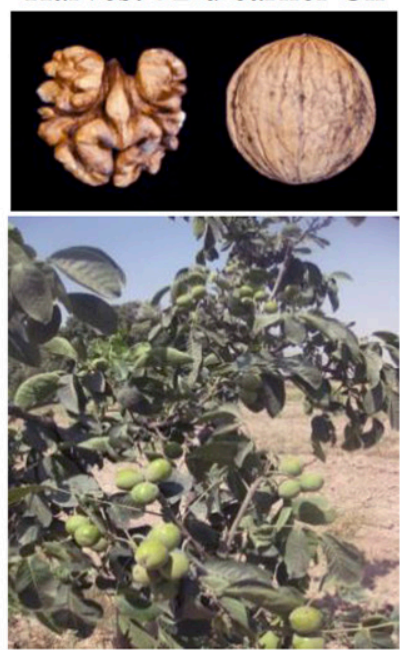

Fig. 1. Fruit of newly released walnut cultivars at maturity in Iran. ${ }^{*} \mathrm{Ch}$, Chandler.

'Caspian'. 'Caspian' is characterized by a relatively late leafing property, which helps it to avoid late-spring frosts. This variety leafs out at the same time as 'Chandler' (Supplemental Table 1, Supplemental Fig. 1 ). The protogynous flowering habit of 'Caspian' allows it to cross-pollinate with 'Chandler' (Supplemental Fig. 1). It has a lateral bearing habit (Fig. 1), and lateral buds are $60 \%$ to $80 \%$ fruitful. 'Caspian' yield is high and very similar to 'Chandler' (Supplemental Table 1). Nut weight is medium (average, 9.2 g). It has a thin shell $(0.99 \mathrm{~mm})$ and a kernel that consists of $\approx 56 \%$ of the nut weight (Supplemental Table 2). Plumpness, light and extralight color, along with good removal are the most important traits of the 'Caspian' kernel. Its ripening time is early-medium, $23 \mathrm{~d}$ earlier than 'Chandler' (Supplemental Table 1, Supplemental Fig. 1). This cultivar has intermediate vigor and is moderately resistant to anthracnose and blight.

'Chaldoran'. 'Chaldoran' has a tree with intermediate vigor, and precocious and high fruit-bearing potential (Supplemental Table 1, Fig. 1; Rezaee et al., 2008). The lateral buds are $90 \%$ to $100 \%$ fruitful. The nuts are large (average weight, $13 \mathrm{~g}$ ) (Supplemental Tables 1 and 2). The leafing date is early to medium, and products may get damaged by late-spring frost, but because this cultivar has a long flowering period, it can produce enough crop after spring frosts when pollen is available. 'Chaldoran' is early ripening (Supplemental Fig. 1). Kernels are large and include $56 \%$ of the nut weight. The kernel is an amber color and is removed easily from the shell (Supplemental Table 2). This cultivar is moderately tolerant to blight as well as anthracnose.

'Alvand'. Tree growth vigor is very low in 'Alvand' (Fig. 1). This feature makes the cultivar suitable to be planted densely, at distances of 4 to $5 \mathrm{~m}$. 'Alvand' is precocious, has a good bearing potential on lateral buds (Fig. 1), and $90 \%$ to $100 \%$ of the buds are fruitful (Supplemental Table 1). The leafing date is early to medium, and products may be damaged by late-spring frost, but because it has a long flowering period, similar to 'Chaldoran', it could produce enough crops after spring frosts if pollen is available. 'Alvand' is an earlyripening cultivar (Supplemental Fig. 1). Kernels are a medium size (nut weight average, $11.3 \mathrm{~g}$ ), and the kernel weight is $50 \%$ of the nut weight. Kernels are removed easily from the shell (Supplemental Table 2). This cultivar is relatively sensitive to anthracnose, bark canker, and blight.

\section{Availability}

Because of the late leafing and early-tomedium ripening habits of 'Persia' and 'Caspian', they can be recommended for walnut-growing areas with late-spring and early-autumn frosts; however, 'Chaldoran' and 'Alvand' are more suitable for regions with less late-spring frost risk.

'Persia', 'Caspian', 'Chaldoran', and 'Alvand' were released officially in Mar. 2019 by the Horticultural Sciences Research Institute of Iran (Hassani et al., 2019), and are in the stage of propagation.

\section{Literature Cited}

Dastjerdi, R. and D. Hassani. 2009. Response of walnut genotypes to Gnomonia leptostyla (Fr.) Ces. \& de Note. in greenhouse. Seed Plant Improvement J. 25(3):433-449 (in Persian).

Hassani, D., J. Atefi, R. Haghjooyan, R. Dastjerdi, M. Keshavarzi, M. R. Mozaffari, A. Soleimani, A. Rahmanian, F. Nematzadeh, and A. Malmir. 2012a. Damavand, a new Persian walnut cultivar as a pollinizer for Iranian walnut cultivars and genotypes. Seed Plant Improve. J. 281(3):529-531 (in Persian).

Hassani, D., J. Atefi, R. Haghjooyan, R. Dastjerdi, M. Keshavarzi, M. R. Mozaffari, A. Soleimani, A. Rahmanian, F. Nematzadeh, and A. Malmir. 2012b. Jamal, a new Persian walnut cultivar for moderate-cold areas of Iran. Seed Plant Improve. J. 28-1(3):525-528 (in Persian)

Hassani, D., R. Dastjerdi, R. Haghjooyan, A. Soleimani, M. Keshavarzi, J. Atefi, M. Mozaffari, R. Rezaee, A. Fahadan, and A. Rahmanian. 2014. Genetic improvement of Persian walnut (Juglans regia L.) in Iran. Acta Hort. 1050:95-102.

Hassani, D., M.R. Mozaffari, R. Dastjerdi, M. Keshavarzi, A. Soleimani, R. Rezaee, and J. Atefi. 2019. Chaldoran, Alvand, Caspian and Persia as four new Iranian walnut cultivars. National cultivar release reports to Seed and Plant Certification and Registration Institute. $37 \mathrm{p}$.

International Plant Genetic Resources Institute. 1994. Descriptors for walnut (Juglans spp.). International Plant Genetic Resources Institute, Rome, Italy.

International Union for the Protection of New Varieties of Plants. 1999. Guidelines for the conduct of tests for distinctness, uniformity and stability in walnut (Juglans regia L.). International Union for the Protection of New Varieties of Plants, Geneva, Switzerland.

McGranahan, G.H. and C.A. Leslie. 2005. Advances in genetic improvement of walnut at the University of California, Davis. Acta Hort. 705:117-122.

Rezaee, R., G.H. Hassani, D. Hassani, and K. Vahdati. 2008. Morphobiological characteristics of some newly selected walnut genotypes from seedling collection of Kahriz-Orumia. Iran. J. Hort. Sci. Technol. 9(3):205-214.

Silsepur, L., M. Keshavarzi, D. Hassani, and M Hashemi. 2011. Necessity of different walnut organs evaluation for selection of blight resistant cultivars. Iran. J. Plant Pathol. 46(4):325-329.

Soleymani, N., M. Keshavarz, N. Hassan Zadeh, D. Hassani, and A. Soleimani. 2019. Evaluation of relative resistance of some walnut commercial cultivars and promising genotypes to shallow bark canker (Brenneria nigrifluens). Seed Plant Improve. J. 35(1):109-120.

Vahdati, K., M.M. Arab, S. Sarikhani, M. SadatHosseini, C.A. Leslie, and P.J. Brown. 2019. Advances in Persian walnut (Juglans regia L.) breeding strategies, p. 401-472. In: J.M. AlKhayri, S.M. Jain, and D.V. Johnson (eds.) Advances in plant breeding strategies: Nut and beverage crops, Vol. 4. Springer, Cham, Switzerland. 


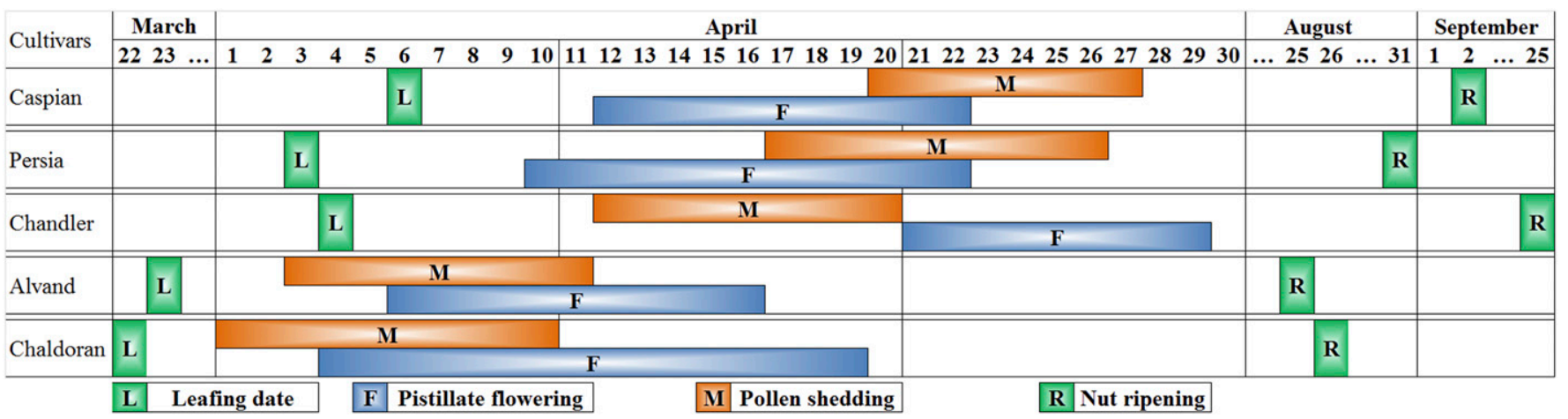

Supplemental Fig. 1. Leafing date, pollen shedding period, female flower receptivity period, and fruit ripening date of four released cultivars: Persia, Caspian, Alvand, and Chaldoran. Reference cultivar: Chandler.

Supplemental Table 1. Tree and phenological characteristics of new walnut cultivars.

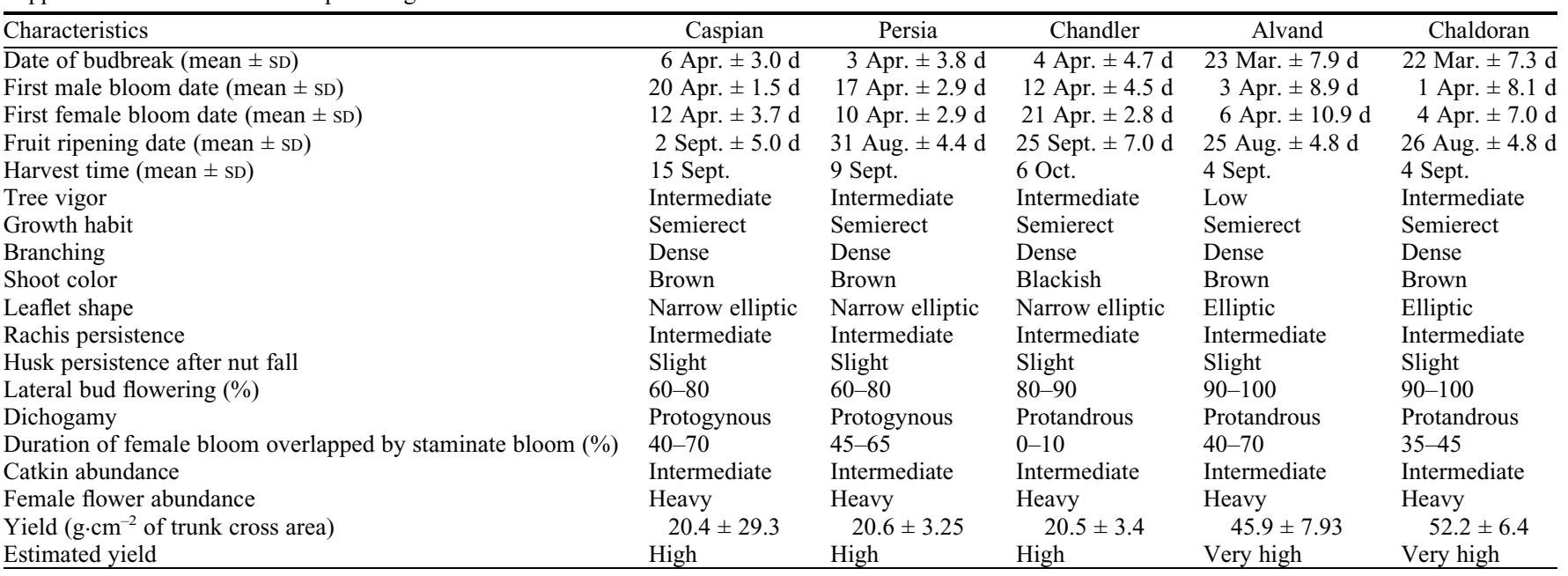

Results are the average of experimental data collected from 2015 to 2018.

Supplemental Table 2. Nut and kernel characteristics of the released walnut cultivars.

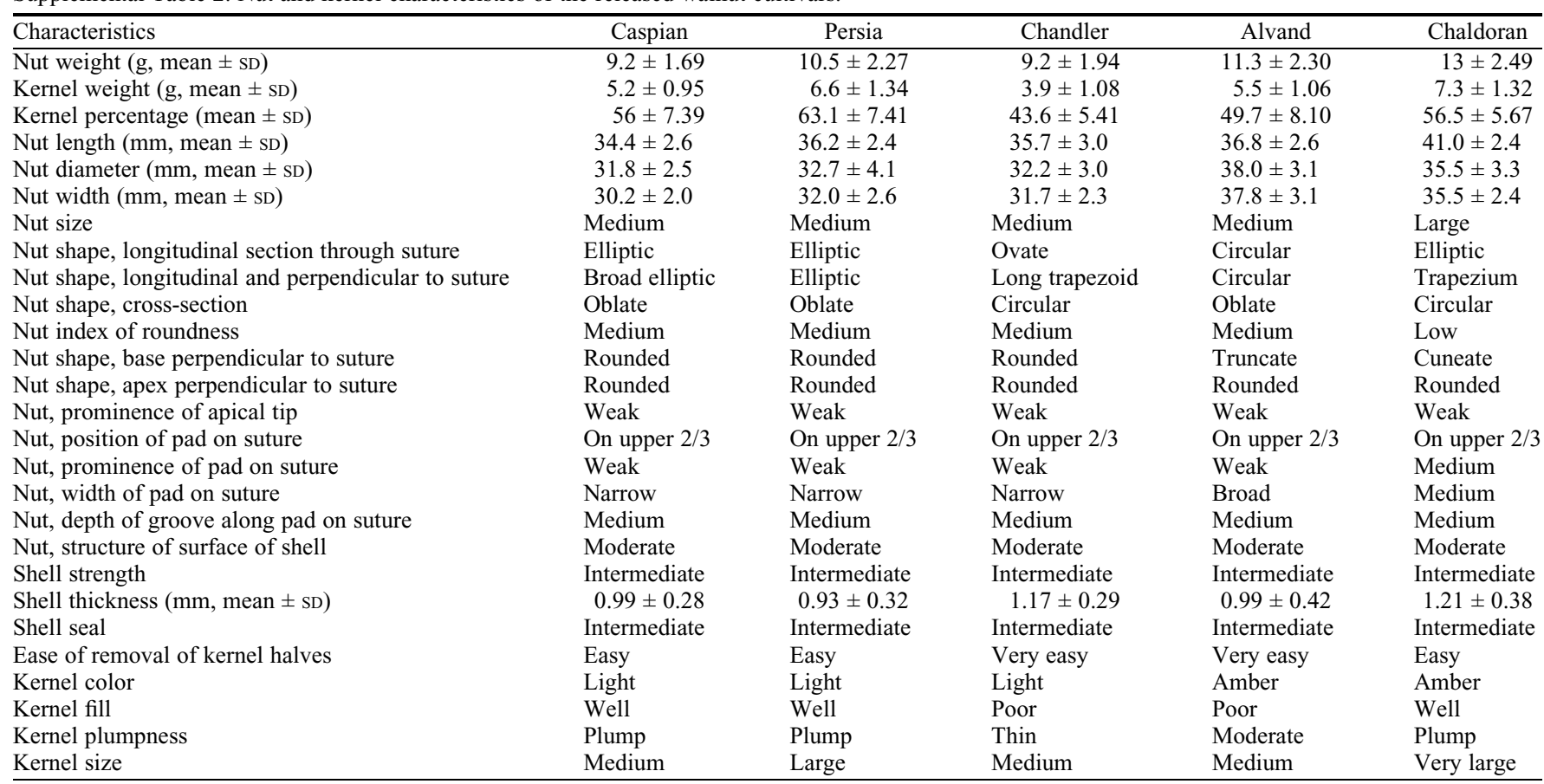

